\title{
Profile of fluticasone furoate/vilanterol dry powder inhaler combination therapy as a potential treatment for COPD
}

REVIEW

This article was published in the following Dove Press journal:

International Journal of COPD

24 February 2014

Number of times this article has been viewed

\section{Gaetano Caramori' \\ Kian Fan Chung ${ }^{2}$ \\ lan M Adcock ${ }^{2}$}

'Centro Interdipartimentale per lo Studio delle Malattie Infiammatorie delle Vie Aeree e Patologie Fumocorrelate (CEMICEF; formerly

Centro di Ricerca su Asma e BPCO), Sezione di Medicina Interna e Cardiorespiratoria, Università di Ferrara, Ferrara, Italy; ${ }^{2}$ Airways Disease Section, National Heart and Lung Institute, Royal Brompton Hospital Biomedical Research Unit, Imperial College London, London, UK
Correspondence: Gaetano Caramori Centro Interdipartimentale per lo Studio delle Malattie Infiammatorie delle Vie Aeree e Patologie Fumocorrelate (CEMICEF; formerly Centro di Ricerca su Asma e BPCO), Sezione di Medicina Interna e Cardiorespiratoria, Dipartimento di Scienze Mediche Università di Ferrara, Via Savonarola 9, 44I 2 I Ferrara, Italy

Tel +390532 210420

Fax +390532 210297

Email gaetano.caramori@unife.it
Abstract: Currently, there is no cure for chronic obstructive pulmonary disease (COPD). The limited efficacy of current therapies for COPD indicates a pressing need to develop new treatments to prevent the progression of the disease, which consumes a significant amount of health care resources and is an important cause of mortality worldwide. Current national and international guidelines for the management of stable COPD patients recommend the use of inhaled long-acting bronchodilators, inhaled corticosteroids, and their combination for maintenance treatment of moderate to severe stable COPD. Once-daily fluticasone furoate/vilanterol dry powder inhaler combination therapy has recently been approved by the US Food and Drug Administration and the European Medicines Agency as a new regular treatment for patients with stable COPD. Fluticasone furoate/vilanterol dry powder inhaler combination therapy has been shown to be effective in many controlled clinical trials involving thousands of patients in the regular treatment of stable COPD. This is the first once-daily combination of ultra-long-acting inhaled $\beta_{2}$-agonists and inhaled glucocorticoids that is available for the treatment of stable COPD and has great potential to improve compliance to long-term regular inhaled therapy and hence to improve the natural history and prognosis of COPD patients.

Keywords: COPD, LABA, ULABA, ICS, bronchodilator, new drugs

\section{Introduction}

The limited efficacy of current therapies for chronic obstructive pulmonary disease (COPD) indicates a pressing need to develop new treatments to prevent the progression of the disease, which consumes a significant amount of health care resources and is an important cause of mortality worldwide.

Current national and international guidelines for the management of stable COPD patients recommend the use of inhaled long-acting bronchodilators, inhaled corticosteroids (ICSs), and their combination for maintenance treatment of moderate to severe stable COPD. ${ }^{1,2}$

Regular treatment of stable COPD patients with long-acting inhaled $\beta_{2}$-agonists (LABAs) alone produces modest increases in lung function with varying effects on health-related quality of life and reduction in symptoms. However, it is also associated with a consistent reduction in exacerbations, which may help people with COPD who suffer frequent deterioration of symptoms prompting health care utilization. ${ }^{3}$ In addition, the evidence is equivocal as to whether or not tiotropium offers greater benefit than LABAs in improving quality of life. Symptom improvement and changes in lung function are similar between the treatment groups. Tiotropium is more effective than LABAs in preventing COPD exacerbations and disease-related hospitalizations, but 
there are no statistical differences between groups in overall hospitalization rates or mortality during the study periods. ${ }^{4}$

A Cochrane review of the role of regular long-term treatment with ICSs alone versus placebo in patients with stable COPD has concluded that it reduces significantly the mean rate of exacerbations and the rate of decline of quality of life but not forced expiratory volume in 1 second $\left(\mathrm{FEV}_{1}\right)$ decline or mortality rates. ${ }^{5}$ ICS treatment is also associated with side effects (such as increased risk of oropharyngeal candidiasis, hoarseness, and pneumonia). ${ }^{5}$

When the clinical efficacy of LABAs alone versus ICSs alone has been compared it has been shown that these two therapies confer similar benefits across the majority of outcomes, including the frequency of exacerbations and mortality. Use of LABAs appears to confer a small additional benefit in terms of improvements in lung function compared with ICSs. On the other hand, ICSs have a small advantage over LABAs in terms of health-related quality of life but are also associated with a dose-related increased risk of pneumonia. ${ }^{6,7}$

Several large controlled clinical trials of inhaled combination therapy with ICSs and LABAs in a single device in stable COPD have shown that this combination therapy is well tolerated and produces a modest but statistically significant reduction in the number of severe exacerbations and improvement in $\mathrm{FEV}_{1}$, quality of life, and respiratory symptoms in stable COPD patients, with no greater risk of side effects than that with use of either component alone. Increased risk of pneumonia is a concern; however, this did not translate into increased exacerbations, hospitalizations, or deaths. ${ }^{8}$

In addition, the Towards a Revolution in COPD Health (TORCH) study showed a $17 \%$ relative reduction in mortality over 3 years for patients receiving salmeterol (SAL)/ fluticasone propionate (FP), although this just failed to reach significance. ${ }^{9}$ Furthermore, systematic reviews of the literature suggest that a combination of ICSs and LABAs reduces mortality by approximately $20 \%$, whereas neither tiotropium nor LABA by itself modifies all-cause mortality in COPD. ${ }^{10}$ ICSs have been found to be associated with a reduction in mortality rate when compared with LABAs among patients with COPD. ${ }^{11}$ However, ICS/LABA combination therapy did not provide any additional benefit on mortality when compared with ICS monotherapy. ${ }^{12}$

A recent Cochrane review of the field has concluded that combined inhaler therapy led to around a quarter fewer COPD exacerbations than were seen with placebo. Current evidence does not suggest any major differences between inhalers in terms of effects; however, nor is the evidence strong enough to demonstrate that all these combinations are equivalent. ${ }^{8}$

The development of improved LABAs has focused on once-daily agents (termed ultra-LABAs [ULABAs]) like indacaterol and olodaterol, which have been proved to be more effective compared with twice-daily dosing with a good safety profile. ${ }^{13-17}$

Just as for LABAs, the development of improved ICSs has focused on once-daily agents to allow regular treatment of patients with stable COPD with once-daily dual-therapy combined inhalers. ${ }^{18}$

There are many new ULABAs and once-daily ICSs under preclinical or early clinical development. ${ }^{13-18}$ We will review here the preclinical and clinical profile of once-daily fluticasone furoate/vilanterol trifenatate (FF/VI) dry powder inhaler (DPI) combination therapy, which has recently been approved by the US Food and Drug Administration and the European Medicines Agency as a new regular treatment for patients with stable COPD. ${ }^{19,20}$

\section{Pharmacodynamics of fluticasone furoate and vilanterol Fluticasone furoate}

The anti-inflammatory actions of glucocorticoids occur through activation of glucocorticoid receptors (GRs), which are members of the nuclear hormone receptors family and are found in the cytoplasm of virtually all cells. ${ }^{21,22}$ GRs are predominantly localized to the airway epithelium, alveolar macrophages, and endothelium, which are therefore probably important sites for the anti-inflammatory action of glucocorticoids, especially those delivered by the inhaled route. The GR gene encodes many protein isoforms. A cytoplasmic alpha form (GR $\alpha$ ), which binds hormone, translocates to the nucleus and regulates gene transcription, and a nuclear localized beta isoform (GR $\beta$ ), which is much less abundant in the cells, does not bind known ligands and, despite ongoing controversy, appears to attenuate GR $\alpha$ action when overexpressed. ${ }^{23,24}$ Glucocorticoids bind to and activate the cytosolic GR, which then translocates into the nucleus. Within the nucleus, GRs can act as a positive transcription factor by forming homodimers of two GR subunits, which bind to specific DNA elements (glucocorticoid response elements) in the promoter regions of glucocorticoid-responsive genes. Several genes are upregulated by glucocorticoids, including the $\beta_{2}$-adrenergic receptor $\left(\beta_{2}\right.$-AR). However, in inflammation, the major role of glucocorticoids appears to be gene repression. ${ }^{21,22}$ The major anti-inflammatory action 
of glucocorticoids is the repression of the proinflammatory actions of nuclear factor kappaB (NF- $\mathrm{BB})$, resulting in a reduction in inflammatory gene transcription. Functionally, glucorticoids act by suppressing airway hyper-responsiveness, reducing airway edema and the infiltration of inflammatory cells from the blood to the airway and thereby reducing the lower airway inflammatory response. ${ }^{21}$

FF (formerly drug code GW685698) is a novel enhancedaffinity synthetic trifluorinated glucocorticoid. ${ }^{25} \mathrm{X}$-ray crystallography comparison studies of its structure with that of dexamethasone and FP have demonstrated that the 17- $\alpha$ furoate ester occupies more fully the lipophilic 17- $\alpha$ pocket on the ligand binding domain of GR, and this may account for the enhanced GR binding of $\mathrm{FF}^{26}$

In fact, in vitro $\mathrm{FF}$ has a fast association and a slow dissociation from the GR, resulting in a relative receptor affinity (RRA) of 30 with reference to dexamethasone (RRA $=1$ ), which is superior to budesonide (RRA $=8)$, ciclesonide's active metabolite des-ciclesonide (RRA =12), FP (RRA =18), and mometasone furoate $(\mathrm{RRA}=22){ }^{27}$

Furthermore, both FP and FF have pronounced retention (without instability or chemical modification) in human lung tissue in vitro, like budesonide, whereas mometasone furoate has the lowest human lung tissue binding. ${ }^{27}$

In addition, FF has very potent glucocorticoid activity in several key pathways downstream of the GR, including the transrepression NF- $\kappa \mathrm{B}$ pathway, the transactivation of the glucocorticoid response element pathway, and the inhibition of the proinflammatory cytokine tumor necrosis factor- $\alpha$, and, unlike FP, FF action is resistant to oxidative stress. ${ }^{25,28}$

FF has similar or slightly higher potency to FP and is twofold to ninefold more potent than budesonide in inhibiting inflammatory cytokine production in epithelial cell lines, primary bronchial epithelial cells, and a monocytic cell line (U937). In addition, FF has superior effects to FP in peripheral blood mononuclear cells from patients with COPD and also in U937 cells or primary bronchial epithelial cells under conditions of oxidative stress. ${ }^{28}$

FF has a longer duration of action in several cell systems compared with FP and budesonide, resulting in prolonged action and 24-hour coverage with once-daily dosing. ${ }^{28}$

The activated GR is detectable in the nucleus of FFtreated epithelial cell lines for at least 30 hours, and FF has a longer duration of action than FP in inhibiting activation of proinflammatory transcription factors such as NF- $\kappa \mathrm{B}$ and activator protein $1 .^{28}$

In vivo in healthy male subjects, in comparison with inhaled FP, inhaled FF (independent of its formulation) demonstrated prolonged absorption from the lung into the systemic circulation, indicating a longer lung retention time and suggesting the potential for maintained efficacy with once-daily administration..$^{29,30}$

\section{Vilanterol}

$\beta_{2}$-agonists are effective bronchodilators, due primarily to their ability to relax airway smooth muscle. ${ }^{13,15}$ In addition to prolonged bronchodilation, LABAs exert other $\beta_{2}$-agonistmediated effects in vitro that may be of clinical relevance in patients with COPD. These include inhibition of airway smooth muscle cell proliferation and inflammatory mediator release, as well as non-smooth muscle effects, such as stimulation of mucociliary transport, reduction of the bronchial epithelial damage caused by bacterial toxins, and attenuation of neutrophil recruitment and activation. ${ }^{31}$

Inhaled $\beta_{2}$-agonists target $\beta_{2}$-ARs expressed in high numbers $\left(3-4 \times 10^{4}\right.$ per cell) on the airway smooth muscle cells of the large and small airways (their number increases with increasing airway generation) and also on other important target cells, including lower airway epithelium (with the highest levels expressed on the type 1 and 2 alveolar cells) and submucosal glands, vascular smooth muscle, macrophages, neutrophils, lymphocytes, eosinophils, mast cells, and the endothelium of the postcapillary venules. ${ }^{13,32}$

Ligand binding to the $\beta_{2}$-AR results in activation of receptor-associated G-stimulatory proteins and enhanced coupling with the enzyme adenylyl cyclase, which leads to increased production of cyclic adenosine monophosphate (cAMP), leading to relaxation of airway smooth muscle..$^{15,21,22,33}$

$\beta_{2}$-agonists may also influence gene transcription. cAMP causes translocation of the catalytic subunit of the protein kinase $\mathrm{A}$ to the nucleus, where it phosphorylates and activates the transcription factor cAMP response element binding protein, enhancing its DNA-binding and transactivating activity. Activation of the $\beta_{2}$-AR can also lead to stimulation of the extracellular signal-regulated kinases/mitogen-activated protein kinases (MAPK) pathway. Activation of the $\beta_{2}-\mathrm{AR}$ can also induce p38 MAPK activation in a manner similar to that seen with extracellular signal-regulated kinases/MAPK activation. ${ }^{15,21,22,33}$

$\beta_{2}$-agonists may also potentiate in the lower airways of patients with COPD the molecular mechanism of glucocorticoid actions, with increased nuclear localization of GRs and additive or sometimes synergistic suppression of inflammatory mediator release. ${ }^{34}$ Activation of CAAT/ enhancer-binding protein by inhaled long-acting $\beta_{2}$-agonists in airway smooth muscle cells has been proposed to account, 
at least in part, for the enhanced effect of this combination treatment in asthmatic patients. ${ }^{35}$

Vilanterol trifenatate (formerly named compound $13 \mathrm{f}$. triphenylacetate or GSK-642444) is a novel ULABA that has been synthesized by incorporation of an oxygen atom at the homobenzylic position of the right-hand-side phenyl ring of (R)-SAL and has suitable chemical properties for inhaled administration. ${ }^{36}$

The affinity of VI for the $\beta_{2}$-AR is higher than formoterol, indacaterol, and olodaterol but comparable with that of SAL. ${ }^{13,37} \mathrm{VI}$ is a highly lipophilic molecule partitioning into cell membrane and forming depots of drug in the cell membrane, but it is not possible to rule out that vilanterol binds directly to an anchored binding site within the $\beta_{2}-\mathrm{AR} .^{37}$

In functional activity studies, VI has a similar selectivity profile as SAL for $\beta_{2}$-AR over $\beta_{1}$-AR and $\beta_{3}$-AR, but a significantly improved selectivity profile than albuterol (salbutamol), formoterol, and indacaterol, decreasing the risk of untoward effects due to the stimulation of the other $\beta$-ARs. ${ }^{13,37}$

VI also has a level of intrinsic efficacy (an agonist of high intrinsic efficacy might offer advantages in clinical effectiveness over a weak partial agonist) ${ }^{38}$ comparable with indacaterol but significantly greater than that of SAL. In in vitro cell-based studies, VI has a persistence of action comparable with indacaterol and longer than formoterol and SAL. ${ }^{13,37}$

VI has a rapid turnover because it is rapidly metabolized by the human liver microsomes. ${ }^{36} \mathrm{VI}$, formoterol, and indacaterol have a more rapid onset of activity compared with SAL. In human airways preconstricted with histamine, VI has a significantly faster onset of action (3.1 minutes) compared with SAL (8.3 minutes). ${ }^{13}$ In vitro in human airways, VI has longer duration of action than SAL, exhibiting a significant level of bronchodilation 22 hours after treatment. ${ }^{37}$

Together, this results in VI having in vivo a dosedependent rapid bronchodilation in healthy subjects and in patients with stable COPD, which is maintained over 24 hours. ${ }^{39,40}$ In asthmatic patients there is no bronchodilation advantage over a 24-hour period of vilanterol twice-daily versus once-daily dosing for the same total daily dose. ${ }^{41}$

\section{Pharmacokinetics of fluticasone furoate and vilanterol}

Following intranasal administration of FF, most of the swallowed dose undergoes incomplete absorption and extensive first-pass metabolism in the liver by the hepatic cytochrome P450 isozyme CYP3A4, resulting in negligible systemic exposure (oral bioavailability is $<0.5 \%$ ). At the highest recommended intranasal dosage, plasma concentrations of FF are typically not quantifiable, despite the use of a highly sensitive high-performance liquid chromatography-mass spectrometry assay in subjects of all ages. ${ }^{42}$ Concomitant administration of strong CYP3A4 inhibitors like ketoconazole increases the plasma concentrations of both FF and VI. ${ }^{43}$

Using pharmacokinetic studies performed in normal subjects and asthmatic patients, the models predict that an FF area under the concentration-time curve over 24 hours postdose of $1,000 \mathrm{pg} \cdot$ hour $/ \mathrm{mL}$ would be required to reduce 24-hour serum cortisol or 24-hour urine cortisol excretion by $20 \%$ and $17 \%$, respectively. ${ }^{44}$

FF inhalation is associated with reduced serum cortisol in patients with moderate hepatic impairment, suggesting that caution should be exercised when prescribing FF/VI in patients with moderate or severe hepatic impairment, due to a risk for unwanted systemic glucocorticoid effects associated with increased FF systemic exposure. ${ }^{45}$ However, hepatic function impairment has no effect on VI systemic exposure. $^{45}$

FF is not detectable $(<1 \%)$ in the urine of healthy subjects following intranasal dosing, and severe renal function impairment has no clinically relevant effects on the pharmacokinetic or pharmacodynamic properties or tolerability of FF/VI. ${ }^{42,45}$

\section{Clinical efficacy of fluticasone furoate/vilanterol dry powder inhaler combination therapy versus placebo in the regular treatment of stable COPD \\ Effect on lung function, symptoms, and exercise tolerance}

Given once daily to patients with moderate to severe stable COPD, inhaled FF/VI combination improved trough $\mathrm{FEV}_{1}$ by more than $200 \mathrm{~mL}$ in two 28-day trials versus placebo. ${ }^{46,47}$ However, a more modest increase (100-130 mL) was seen in two longer 12 to 28 -week trials. ${ }^{48-51}$ The regular treatment of stable COPD patients with FF/VI combination decreases their symptoms, particularly dyspnea, in two 12 to 28 -week trials, but there are no published studies on the effect of this therapy on exercise tolerance of stable patients with COPD. ${ }^{46-48,50-52}$ 


\section{Prevention of COPD exacerbations, accelerated $\mathrm{FEV}$, decline, long-term compliance to inhaled therapy, and mortality}

In the two longest trials of 1-year duration involving more than 3,000 patients with stable moderate to severe COPD randomized to FF/VI or VI alone, the treatment with FF/VI was associated with a slight (27\%) but significant decrease (0.81 versus [vs] 1.11) in the yearly rate of moderate plus severe COPD exacerbations, the time to first moderate or severe exacerbation, and the frequency of exacerbations requiring systemic glucocorticoids. There was no difference in the rate of COPD exacerbations requiring hospitalization. ${ }^{52}$

The Study to Understand Mortality and Morbidity in COPD (SUMMIT) aims to determine the impact of FF/VI combination and the individual components on the survival of patients with moderate stable COPD and either a history of cardiovascular disease or those at increased risk for cardiovascular disease. SUMMIT is a multicentre, randomized, double-blind, parallel-group, placebo-controlled trial of 16,000 patients with moderate stable COPD randomly assigned to once-daily treatment with FF/VI (100/25 $\mu \mathrm{g})$, FF $(100 \mu \mathrm{g}), \mathrm{VI}(25 \mu \mathrm{g})$, or matched placebo. Mortality is the primary end point. The study is an event-driven trial powered by the comparison of FF/VI with placebo. Secondary end points are decline in $\mathrm{FEV}_{1}$ and effect on a composite cardiovascular end point. ${ }^{53}$ The study is underway, and it is estimated that it will be completed by July 2015 (http://clinicaltrials.gov/ show/NCT01313676).

There are no published studies on the role of the effect of regular treatment of patients with stable COPD with FF/VI combination in the prevention of their accelerated $\mathrm{FEV}_{1}$ decline and/or in their long-term compliance to the inhaled therapy.

\section{Clinical efficacy of fluticasone furoate/vilanterol dry powder inhaler vs fluticasone propionatel salmeterol combination therapy in the regular treatment of stable COPD}

There are efficacy data comparing FF/VI with FP/SAL combination in the treatment of stable COPD. In one 12-week trial, weighted mean $\mathrm{FEV}_{1}$ (mean $130 \mathrm{~mL}$ ) was greater, and time to $100 \mathrm{~mL}$ improvement was shorter (median
16 minutes) with FF/VI than with FP/SAL (weighted mean $108 \mathrm{~mL}$; median 28 minutes). Health status (St George's Respiratory Questionnaire total score) improved in both groups (FF/VI -4.3 units; FP/SAL -3.0 units), but differences between treatments were not statistically significant. ${ }^{48}$

\section{Anti-inflammatory effect of fluticasone furoate/vilanterol dry powder inhaler combination therapy in the regular treatment of stable COPD}

Airway biopsy studies are required to evaluate whether FF/ VI has a significant in vivo anti-inflammatory activity in the lower airways in addition to its known bronchodilator properties.

\section{Side effects and cost-effectiveness of fluticasone furoate/vilanterol dry powder inhaler combination therapy in the regular treatment of stable COPD}

Unlike other LABAs and ULABAs, vilanterol is not available as a single agent and is marketed only in a fixed combination with $100 \mu \mathrm{g}$ of FF at a dosage of $25 \mu \mathrm{g}$ of vilanterol administered in a new DPI (Ellipta ${ }^{\mathrm{TM}}$; GlaxoSmithKline plc., Brentford, UK) incorporating a dose counter. In one study this new device was associated with high patient satisfaction and was preferred to other DPI and metered dose inhalers, according to an interview of patients with COPD, and this may increase adherence to therapy in COPD. ${ }^{54}$

Like other inhaled $\beta_{2}$-agonists, VI may cause clinically significant cardiovascular effects (including an increase of the pulse rate and of the systemic arterial blood pressure and prolongation of the QT interval of the electrocardiogram [ECG] corrected for the heart rate) and therefore must be used with caution during acute coronary syndromes and in patients with cardiac arrhythmia and/or chronic heart failure. However, the safety of single and repeat VI doses up to $50 \mu \mathrm{g}$ has been established in healthy subjects with no clinically significant abnormalities in vital signs, 12-lead ECG, Holter ECG, blood glucose or potassium, and corrected QT (QTc) observed, ${ }^{55,56}$ but some prolongation of the QTc was seen following the $100 \mu \mathrm{g}$ VI dose after single and repeat doses in healthy subjects. ${ }^{40,56}$

In healthy Japanese subjects, no safety concerns were found following single or repeat dosing of FF, VI, and 
FF/VI. Systemic exposure to FF and VI increases in a dose-dependent manner. In these subjects, serum cortisol level is suppressed by $97 \%$ after 7 days of repeat administration of FF at a dose of $800 \mu \mathrm{g} .{ }^{57}$

The regular treatment of the patients with stable COPD with FF/VI DPI combination is usually well tolerated. The adverse events reported most often in the short- and long-term clinical studies of FF/VI DPI combination therapy versus placebo in the regular treatment of stable COPD include nasopharyngitis (9\%), upper respiratory tract infection $(7 \%)$, headache (7\%), and dysphonia and oropharyngeal candidiasis (5\%). ${ }^{46-52,58}$ However, in the two longest trials of 1 year duration, both pneumonia and bone fractures were seen more frequently with an FF/VI combination therapy than with VI alone. ${ }^{52}$ Although the rate of pneumonia roughly doubled in the groups taking FF, this increase is similar to the increased pneumonia risk described previously with FP and in some studies of budesonide and mometasone. ${ }^{52}$ In addition, the incidence of these events was very low compared with the rate of COPD exacerbations, which was ten times higher. Eight deaths from pneumonia were observed in the FF/VI combination group compared with none in the VI only group. ${ }^{52}$

There are safety data showing that the short-term treatment of stable COPD patients with FF/VI versus FP/SAL combination is equally well tolerated. ${ }^{48}$ The new FF/VI combination must not be used in the treatment of COPD exacerbations or for the treatment of asthmatic patients.

There is no formal cost-effectiveness analysis published on the use of an FF/VI DPI combination versus other combinations in the regular treatment of patients with stable COPD.

\section{Conclusion}

The actual effectiveness achieved in clinical practice with any COPD therapies depends on patients' inhaler technique, adherence, and persistence. ${ }^{59}$ Low adherence to maintenance inhaled therapy is common in COPD and is associated with worst prognosis, ${ }^{60}$ whereas improved adherence to regular treatment is associated with reduced rate of all-cause hospitalization. ${ }^{61}$ In general, frequent dosing and the use of multiple inhalers are associated with low adherence of the patients to long-term inhaled therapy in COPD. ${ }^{62,63} \mathrm{FF} / \mathrm{VI}$ DPI combination therapy has been shown effective in many controlled clinical trials involving thousands of patients in the regular treatment of stable COPD and has recently been approved for this indication by the US Food and Drug Administration and the European Medicines Agency. This is the first once-daily combination of ULABAs and inhaled glucocorticoids available for the treatment of stable COPD and has great potential to improve adherence to long-term regular inhaled therapy and hence to improve the natural history and prognosis of COPD patients.

\section{Disclosure}

The authors report no conflicts of interest in this work.

\section{References}

1. Global Initiative for Chronic Obstructive Lung Disease. Global Strategy for the Diagnosis, Management and Prevention of COPD. NHLBI/WHO workshop report. Bethesda, MD: National Heart, Lung and Blood Institute, April 2001; NIH Publication. No 2701:1-100. Last updated 2014. Available from: http://www.goldcopd.org/guidelines-global-strategyfor-diagnosis-management.html. Accessed January 27, 2014.

2. Qaseem A, Wilt TJ, Weinberger SE, et al; American College of Physicians; American College of Chest Physicians; American Thoracic Society; European Respiratory Society. Diagnosis and management of stable chronic obstructive pulmonary disease: a clinical practice guideline update from the American College of Physicians, American College of Chest Physicians, American Thoracic Society, and European Respiratory Society. Ann Intern Med. 2011;155:179-191.

3. Appleton S, Poole P, Smith B, Veale A, Lasserson TJ, Chan MM. Longacting beta-agonists for poorly reversible chronic obstructive pulmonary disease. Cochrane Database Syst Rev. 2006;(3):CD001104.

4. Chong J, Karner C, Poole P. Tiotropium versus long-acting beta-agonists for stable chronic obstructive pulmonary disease. Cochrane Database Syst Rev. 2012;9:CD009157.

5. Yang IA, Clarke MS, Sim EH, Fong KM. Inhaled corticosteroids for stable chronic obstructive pulmonary disease. Cochrane Database Syst Rev. 2012;7:CD002991.

6. Spencer S, Karner C, Cates CJ, Evans DJ. Inhaled corticosteroids versus long-acting beta-agonists for chronic obstructive pulmonary disease. Cochrane Database Syst Rev. 2011;(12):CD007033.

7. Yawn BP, Li Y, Tian H, Zhang J, Arcona S, Kahler KH. Inhaled corticosteroid use in patients with chronic obstructive pulmonary disease and the risk of pneumonia: a retrospective claims data analysis. Int $J$ Chron Obstruct Pulmon Dis. 2013;8:295-304.

8. Nannini LJ, Poole P, Milan SJ, Holmes R, Normansell R. Combined corticosteroid and long-acting beta2-agonist in one inhaler versus placebo for chronic obstructive pulmonary disease. Cochrane Database Syst Rev. 2013;11:CD003794.

9. Calverley PM, Anderson JA, Celli B, et al; TORCH investigators. Salmeterol and fluticasone propionate and survival in chronic obstructive pulmonary disease. $N$ Engl J Med. 2007;356:775-789.

10. Kliber A, Lynd LD, Sin DD. The effects of long-acting bronchodilators on total mortality in patients with stable chronic obstructive pulmonary disease. Respir Res. 2010;11:56.

11. Dong YH, Lin HH, Shau WY, Wu YC, Chang CH, Lai MS. Comparative safety of inhaled medications in patients with chronic obstructive pulmonary disease: systematic review and mixed treatment comparison meta-analysis of randomised controlled trials. Thorax. 2013;68: 48-56.

12. Cyr MC, Beauchesne MF, Lemière C, Aaron SD, Blais L. Effects of inhaled corticosteroids in monotherapy or combined with long-acting $\beta 2$-agonists on mortality among patients with chronic obstructive pulmonary disease. Ann Pharmacother. 2010;44:613-622.

13. Cazzola M, Page CP, Calzetta L, Matera MG. Pharmacology and therapeutics of bronchodilators. Pharmacol Rev. 2012;64:450-504.

14. Cazzola M, Rogliani P, Segreti A, Matera MG. An update on bronchodilators in Phase I and II clinical trials. Expert Opin Investig Drugs. 2012;21:1489-1501. 
15. Cazzola M, Page CP, Rogliani P, Matera MG. $\beta 2$-agonist therapy in lung disease. Am J Respir Crit Care Med. 2013;187:690-696.

16. Rossi A, Polese G. Indacaterol: a comprehensive review. Int J Chron Obstruct Pulmon Dis. 2013;8:353-363.

17. Spina D. Current and novel bronchodilators in respiratory disease. Curr Opin Pulm Med. 2014;20:73-86.

18. Adcock IM, Caramori G, Kirkham PA. Strategies for improving the efficacy and therapeutic ratio of glucocorticoids. Curr Opin Pharmacol. 2012;12:246-251.

19. Goldenberg MM. Pharmaceutical approval update. Pharmacy and Therapeutics. 2013;38:389-403.

20. http://www.ema.europa.eu [homepage on the Internet]. Accessed January 27, 2014.

21. Caramori G, Adcock IM. Pharmacology of airway inflammation in asthma and COPD. Pulm Pharmacol Ther. 2003;16:247-277.

22. Caramori G, Casolari P, Adcock I. Role of transcription factors in the pathogenesis of asthma and COPD. Cell Commun Adhes. 2013;20:21-40.

23. Ramamoorthy S, Cidlowski JA. Exploring the molecular mechanisms of glucocorticoid receptor action from sensitivity to resistance. Endocr Dev. 2013;24:41-56.

24. Oakley RH, Cidlowski JA. The biology of the glucocorticoid receptor: new signaling mechanisms in health and disease. $J$ Allergy Clin Immunol. 2013;132:1033-1044.

25. Salter M, Biggadike K, Matthews JL, et al. Pharmacological properties of the enhanced-affinity glucocorticoid fluticasone furoate in vitro and in an in vivo model of respiratory inflammatory disease. Am J Physiol Lung Cell Mol Physiol. 2007;293:L660-L667.

26. Biggadike K, Bledsoe RK, Hassell AM, et al. X-ray crystal structure of the novel enhanced-affinity glucocorticoid agonist fluticasone furoate in the glucocorticoid receptor-ligand binding domain. $J$ Med Chem. 2008;51:3349-3352.

27. Valotis A, Högger P. Human receptor kinetics and lung tissue retention of the enhanced-affinity glucocorticoid fluticasone furoate. Respir Res. 2007;8:54

28. Rossios C, To Y, To M, et al. Long-acting fluticasone furoate has a superior pharmacological profile to fluticasone propionate in human respiratory cells. Eur J Pharmacol. 2011;670:244-251.

29. Allen A, Bal J, Cheesbrough A, Hamilton M, Kempsford R. Pharmacokinetics (PK) and pharmacodynamics (PD) of intravenous and inhaled fluticasone furoate (FF) in healthy Caucasian and East Asian subjects. Br J Clin Pharmacol. Epub October 24, 2013.

30. Allen A, Bareille PJ, Rousell VM. Fluticasone furoate, a novel inhaled corticosteroid, demonstrates prolonged lung absorption kinetics in man compared with inhaled fluticasone propionate. Clin Pharmacokinet. 2013;52:37-42.

31. Johnson M, Rennard S. Alternative mechanisms for long-acting B2-adrenergic agonists in COPD. Chest. 2001;120:258-270.

32. Barnes PJ. Distribution of receptor targets in the lung. Proc Am Thorac Soc. 2004;1:345-351.

33. Chung KF, Caramori G, Adcock IM. Inhaled corticosteroids as combination therapy with beta-adrenergic agonists in airways disease: present and future. Eur J Clin Pharmacol. 2009;65:853-871.

34. Haque R, Hakim A, Moodley T, et al. Inhaled long-acting $\beta 2$ agonists enhance glucocorticoid receptor nuclear translocation and efficacy in sputum macrophages in COPD. J Allergy Clin Immunol. 2013;132:1166-1173.

35. Roth M, Johnson PR, Rüdiger JJ, et al. Interaction between glucocorticoids and beta2 agonists on bronchial airway smooth muscle cells through synchronised cellular signalling. Lancet. 2002;360:1293-1299.

36. Procopiou PA, Barrett VJ, Bevan NJ, et al. Synthesis and structureactivity relationships of long-acting $\beta 2$ adrenergic receptor agonists incorporating metabolic inactivation: an antedrug approach. $J$ Med Chem. 2010;53:4522-4530.

37. Slack RJ, Barrett VJ, Morrison VS, et al. In vitro pharmacological characterization of vilanterol, a novel long-acting $\beta 2$-adrenoceptor agonist with 24-hour duration of action. J Pharmacol Exp Ther. 2013;344:218-230.
38. Hanania NA, Sharafkhaneh A, Barber R, Dickey BF. Beta-agonist intrinsic efficacy: measurement and clinical significance. Am J Respir Crit Care Med. 2002;165:1353-1358.

39. Hanania NA, Feldman G, Zachgo W, et al. The efficacy and safety of the novel long-acting $\beta 2$ agonist vilanterol in patients with COPD: a randomized placebo-controlled trial. Chest. 2012;142:119-127.

40. Kempsford R, Norris V, Siederer S. Vilanterol trifenatate, a novel inhaled long-acting beta2 adrenoceptor agonist, is well tolerated in healthy subjects and demonstrates prolonged bronchodilation in subjects with asthma and COPD. Pulm Pharmacol Ther. 2013;26:256-264.

41. Sterling R, Lim J, Frith L, Snowise NG, Jacques L, Haumann B. Efficacy and optimal dosing interval of the long-acting beta ${ }_{2}$ agonist, vilanterol, in persistent asthma: a randomised trial. Respir Med. 2012;106: $1110-1115$.

42. Kumar R, Kumar D, Parakh A. Fluticasone furoate: a new intranasal corticosteroid. J Postgrad Med. 2012;58:79-83.

43. Kempsford R, Allen A, Bal J, Rubin D, Tombs L. The effect of ketoconazole on the pharmacokinetics and pharmacodynamics of inhaled fluticasone furoate and vilanterol trifenatate in healthy subjects. Br J Clin Pharmacol. 2013;75:1478-1487.

44. Allen A. The relationship between fluticasone furoate systemic exposure and cortisol suppression. Clin Pharmacokinet. 2013;52:885-896.

45. Allen A, Davis A, Hardes K, Tombs L, Kempsford R. Influence of renal and hepatic impairment on the pharmacokinetic and pharmacodynamic properties and tolerability of fluticasone furoate and vilanterol in combination. Clin Ther. 2012;34:2316-2332.

46. Boscia JA, Pudi KK, Zvarich MT, Sanford L, Siederer SK, Crim C. Effect of once-daily fluticasone furoate/vilanterol on 24-hour pulmonary function in patients with chronic obstructive pulmonary disease: a randomized, three-way, incomplete block, crossover study. Clin Ther. 2012;34:1655-1666.

47. Lötvall J, Bakke PS, Bjermer L, et al. Efficacy and safety of 4 weeks' treatment with combined fluticasone furoate/vilanterol in a single inhaler given once daily in COPD: a placebo-controlled randomised trial. $B M J$ Open. 2012;2:e000370.

48. Agustí A, de Teresa L, De Backer W, et al. A comparison of the efficacy and safety of once-daily fluticasone furoate/vilanterol with twice-daily fluticasone propionate/salmeterol in moderate to very severe COPD. Eur Respir J. Epub October 10, 2013.

49. Bollmeier SG, Prosser TR. Combination of fluticasone furoate and vilanterol for the treatment of chronic obstructive pulmonary disease. Ann Pharmacother. Epub November 19, 2013.

50. Kerwin EM, Scott-Wilson C, Sanford L, et al. A randomised trial of fluticasone furoate/vilanterol $(50 / 25 \mu \mathrm{g} ; 100 / 25 \mu \mathrm{g})$ on lung function in COPD. Respir Med. 2013;107:560-569.

51. Martinez FJ, Boscia J, Feldman G, et al. Fluticasone furoate/vilanterol $(100 / 25 ; 200 / 25 \mu \mathrm{g})$ improves lung function in COPD: a randomised trial. Respir Med. 2013;107:550-559.

52. Dransfield MT, Bourbeau J, Jones PW, et al. Once-daily inhaled fluticasone furoate and vilanterol versus vilanterol only for prevention of exacerbations of COPD: two replicate double-blind, parallel-group, randomised controlled trials. Lancet Respir Med. 2013;1:210-223.

53. Vestbo J, Anderson J, Brook RD, et al. The Study to Understand Mortality and Morbidity in COPD (SUMMIT) study protocol. Eur Respir J. 2013;41:1017-1022.

54. Svedsater H, Dale P, Garrill K, Walker R, Woepse MW. Qualitative assessment of attributes and ease of use of the ELLIPTATM dry powder inhaler for delivery of maintenance therapy for asthma and COPD. $B M C$ Pulm Med. 2013;13:72.

55. Kelleher DL, Mehta RS, Jean-Francois BM, et al. Safety, tolerability, pharmacodynamics and pharmacokinetics of umeclidinium and vilanterol alone and in combination: a randomized crossover trial. PLOS One. 2012;7:e50716.

56. Kempsford R, Allen A, Kelly K, Saggu P, Crim C. A repeat-dose thorough QT study of inhaled fluticasone furoate (FF)/vilanterol (VI) combination in healthy subjects. Br J Clin Pharmacol. Epub October 4, 2013. 
57. Nakahara N, Wakamatsu A, Kempsford R, et al. The safety, pharmacokinetics and pharmacodynamics of a combination of fluticasone furoate and vilanterol in healthy Japanese subjects. Int J Clin Pharmacol Ther. 2013;51:660-671.

58. Hussar DA, Ahmad A. Vilanterol trifenatate/fluticasone furoate, lomitapide mesylate, and mipomersen sodium. J Am Pharm Assoc. 2013;53:662-670.

59. Fromer L, Barnes T, Garvey C, Ortiz G, Saver DF, Yawn B. Innovations to achieve excellence in COPD diagnosis and treatment in primary care. Postgrad Med. 2010;122:150-164.

60. Vestbo J, Anderson JA, Calverley PM, et al. Adherence to inhaled therapy, mortality and hospital admission in COPD. Thorax. 2009;64: 939-943.
61. Simoni-Wastila L, Wei YJ, Qian J, et al. Association of chronic obstructive pulmonary disease maintenance medication adherence with all-cause hospitalization and spending in a Medicare population. Am J Geriatr Pharmacother. 2012;10:201-210.

62. Ágh T, Inotai A, Mészáros Á. Factors associated with medication adherence in patients with chronic obstructive pulmonary disease. Respiration. 2011;82:328-334.

63. Bourbeau J, Bartlett SJ. Patient adherence in COPD. Thorax. 2008;63: 831-838.

\section{Publish your work in this journal}

The International Journal of COPD is an international, peer-reviewed journal of therapeutics and pharmacology focusing on concise rapid reporting of clinical studies and reviews in COPD. Special focus is given to the pathophysiological processes underlying the disease, intervention programs, patient focused education, and self management protocols.

\section{Dovepress}

This journal is indexed on PubMed Central, MedLine and CAS. The manuscript management system is completely online and includes a very quick and fair peer-review system, which is all easy to use. Visit http://www.dovepress.com/testimonials.php to read real quotes from published authors.

Submit your manuscript here: http://www.dovepress.com/international-journal-of-copd-journal 